\title{
ASSOCIATED FAUNA OF Prasiola crispa (CHLOROPHYTA) RELATED TO PENGUIN ROOKERY AT ARCTOWSKI (KING GEORGE ISLAND, SOUTH SHETLAND ISLANDS, MARITIME ANTARCTIC)
}

http://dx.doi.org/10.4322/apa.2014.048

Adriana Galindo Dalto ${ }^{1,2,{ }^{*},}$ Geyze Magalhães de Faria ${ }^{1,3}$, Caio Amitrano de Alencar Imbassahy ${ }^{1}$, Tais Maria de Souza Campos ${ }^{1,4}$, Yocie Yoneshigue-Valentin

\author{
'Laboratório de Macroalgas Marinhas, Departamento de Botânica, \\ Instituto de Biologia, Universidade Federal do Rio de Janeiro - UFRJ \\ ${ }^{2}$ Postdoctoral Researcher (CAPES/FAPERJ Fellow) \\ ${ }^{3} \mathrm{DTI}-3$ Fellow (CNPq/INCT-APA) \\ ${ }^{4}$ Scientific Initiation Fellow (CNPq/INCT-APA) \\ *e-mail: agdalto@gmail.com
}

Abstract: The samples of Prasiola crispa for study of associated fauna were collected on the rocks in the region adjacent to the penguin rookery at the Henri Arctowski Polish Research Station at (Admiralty Bay, Antarctic). The preliminary results showed that Tardigrades and Nematodes are the most abundant organisms of the associated fauna of P. crispa, being found in extremely high density. Others invertebrates were found in low densities $\left(<70\right.$ ind. $\left.\mathrm{cm}^{-2}\right)$ along with Acari, Rotifer and Collembola. The specific identifications are still underway, however, the results obtained so far are suggesting that the density and the diversity of the microfauna of P. crispa is strongly conditioned by ice-melt water and the degree of humidity in the thallus of this alga.

Keywords: meiofauna, tardigrade, terrestrial communities

\section{Introduction}

Prasiola crispa is a nitrophilous green algae that occurs especially in the supralittoral zone or in free ice areas subject to sea water spray, located near seabird colonies, where they benefit from the guano (Figures 1 and 2). In these areas, P. crispa develop forming overlapping blades that can reach up to 3 inches tall and is distributed in spots 10 to $15 \mathrm{~cm}$ long on rocks and soil enriched with nutrients (ornithogenic soils), with the capacity of forming extensive mats that stretch over some meters. Because of it morphological characteristics, the thallus of $P$. crispa is suitable for the formation of a micro-habitat that favours the development of a sizeable community of micro invertebrates, especially in extreme environments such as Antarctica.
The community of terrestrial invertebrates associated to the vegetation of ice-free areas consist mainly of Rotifer, Nematode, Tardigrade and Microarthropodes such as Collembola and Acari. Many of these invertebrates are particularly well studied and documented for this environment, such as Collembola and Acari (i.e. Worland \& Lukesová, 2000; Stevens \& Hogg, 2002; Sinclair et al., 2006; Schulte et al., 2008), others, such as Tardigrade, Nematode, Rotifer are particularly poorly studied in the Antarctic region. Presently, it is known that the Antarctic terrestrial biota has low diversity, a high degree of endemism and clear patterns of biogeographic distribution, defined by consistent biological and climatic differences (Convey \& McInnes, 


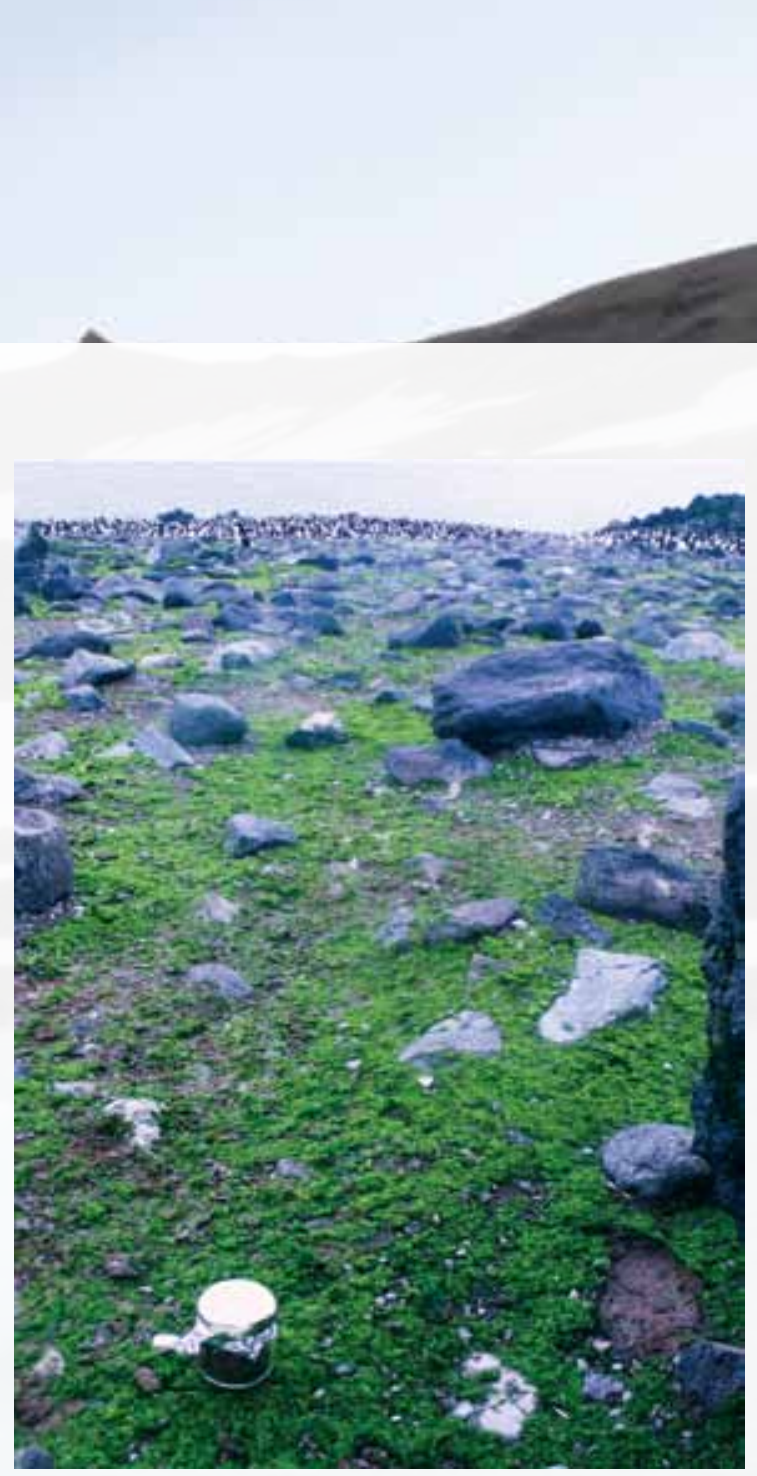

Figure 1. Prasiola crispa mats in the Arctowski Polish Station. Photo: Erli Costa.

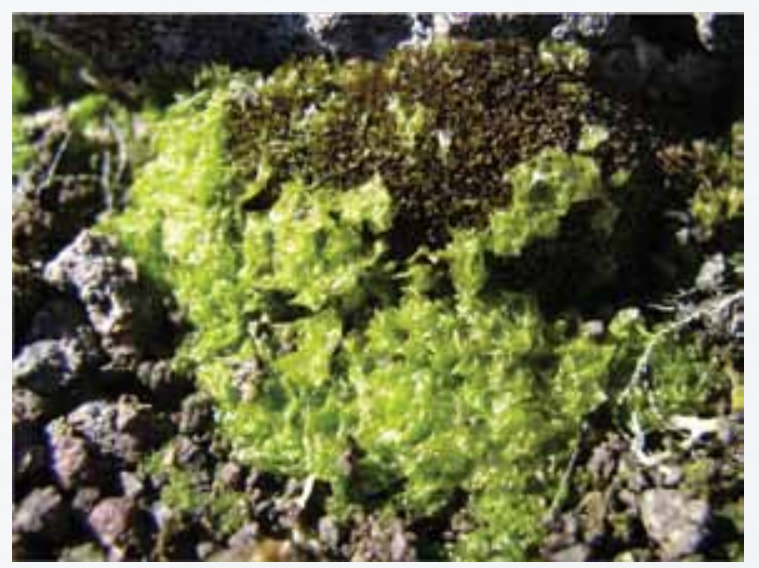

Figure 2. Prasiola crispa (Chlorophyta) associated to Syntrichia magellanica (Bryopsida Class). Photo: Lubomir Kovacik.

2005; Convey \& Stevens, 2007). Added to this, the Antarctic terrestrial biota include organisms ecophysiology adapted to environmental pressures involving very low temperatures, nutrient limitation, environmental radiation, lack of liquid water, desiccation and physical abrasion (Convey et al.,
2008). Recent studies have shown that this biota has an ancient origin and has persisted in isolation for ten million years (Convey \& Stevens, 2007; Convey et al., 2009; Chow \& Convey, 2007). These characteristics result in the terrestrial communities of Antarctica being particularly sensitive to the effects of human presence in the region and to climate change.

In this context, this paper aims to contribute to the knowledge of the terrestrial invertebrate fauna associated to Prasiola crispa of ice-free areas in the coastal region around the Admiralty Bay (King George Island, South Shetland, Antarctica). Firstly this study was focused on the knowledge of the fauna, and in a second instance has the intention of giving emphasis to ecological aspects related to the establishment of these microfaunistic communities.

\section{Materials and Methods}

The samples of Prasiola crispa were collected from the rocks adjacent to the penguin rookeries of Henri Arctowski Polish Research Station (Admiralty Bay, King George Island) during the XXIX Brazilian Antarctic Operation (in January 2011) (Figure 3). Three samples of approximately $3 \mathrm{~cm}^{2}$ were observed in vivo and later preserved in $4 \%$ formalin for later counting and identification of the associated fauna. In laboratory the organisms were separated through sieves with meshes of 500 and $38 \mu \mathrm{m}$. The organisms were counted through stereoscopic microscope and identified through optical microscopy. The identification still underway is using as a basis specific pertinent literature and also the examination of specimens by specialists from the National Museum (MN/UFRJ).

\section{Results and Discussion}

The associated microfauna of Prasiola crispa consisted of Rotifer, Nematode, Tardigrade, Acari and Collembola. Tardigrade was the phylum that occurred with greatest density, presenting values of up to 7002.67 ind. $\mathrm{cm}^{-2}$ $\left(X=2842.11\right.$ ind. $\mathrm{cm}^{-2}$ ) (Figure 4$)$. Nematode was the second phylum of greatest density, being found with up to 3965 ind.cm ${ }^{-2}\left(X=1388.89\right.$ ind. $\left.\mathrm{cm}^{-2}\right)$. Acari, Collembola and Rotifera were encountered with densities inferior to 


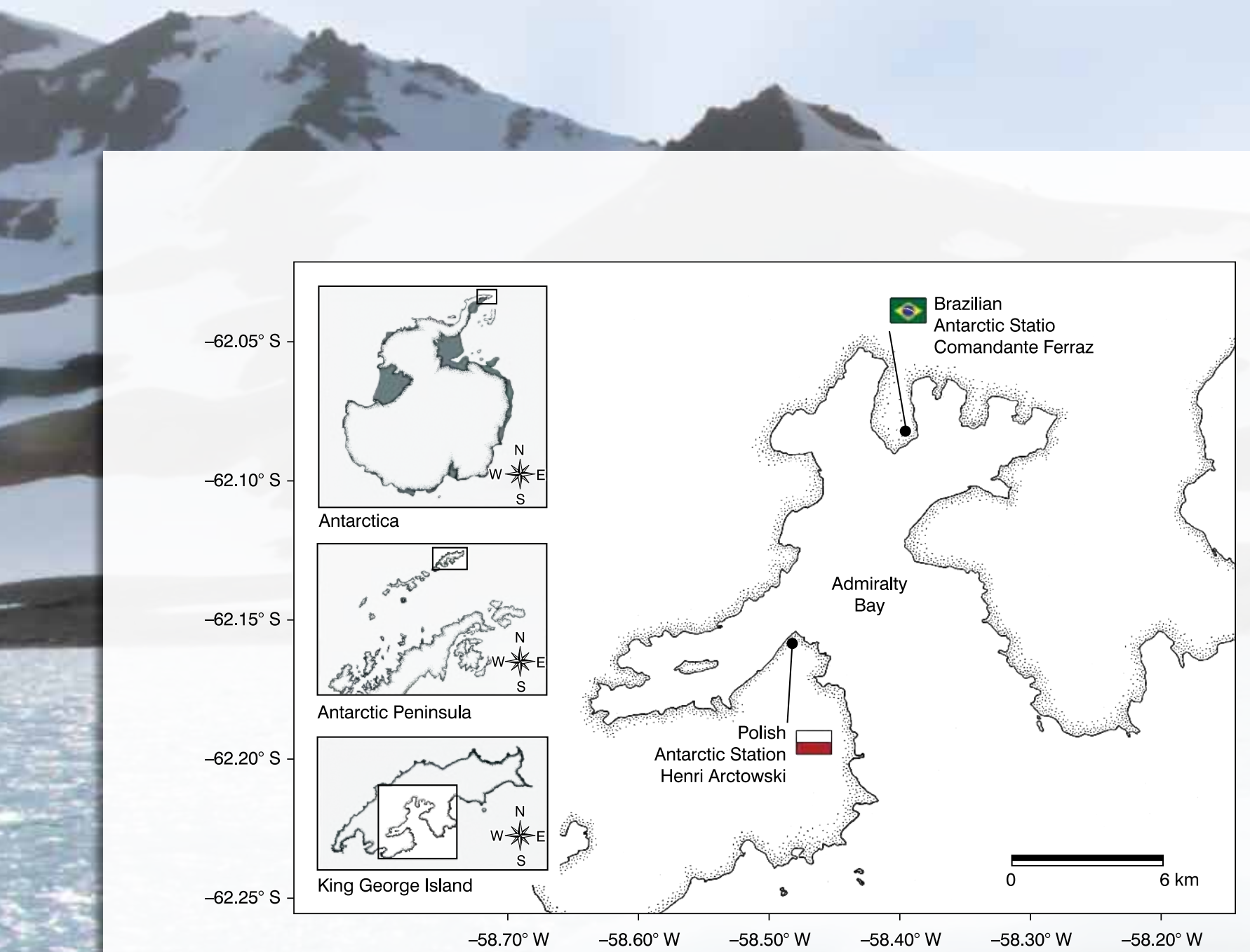

Figure 3. Admiralty Bay (King George Island, South Shetland Islands, Antarctic Peninsula). Illustration: Rafael Bendayan de Moura.
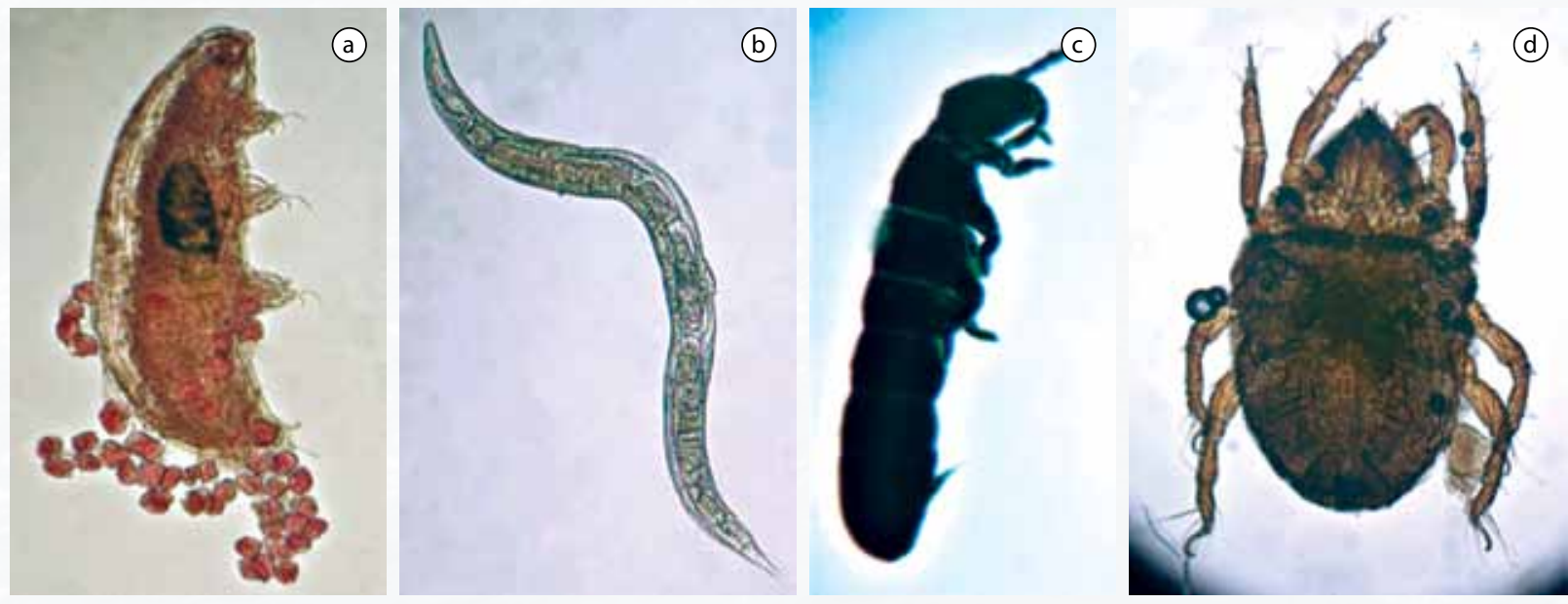

Figure 4. Microfauna associated to Prasiola crispa. a) Tardigrade; b) Nematode; c) Collembola; d) Acarina. Photos: Geyze Faria

70 ind. $\mathrm{cm}^{-2}$ (Table 1). The taxonomic identifications are still underway, however, up to the present time the most abundant organisms have all been identified; amongst them are three species of Collembola (Cryptopgus antarticus,
Fiesia cf. grisea and Friesia sp.) (Figures 5 and 6), one genera of Nematode (Plectidae, genus Plectus) and one genera of Tardigrade (Hypsibiidae, genus Hysibius,) (Figure 7). All the taxa identified up to the present time have already been 


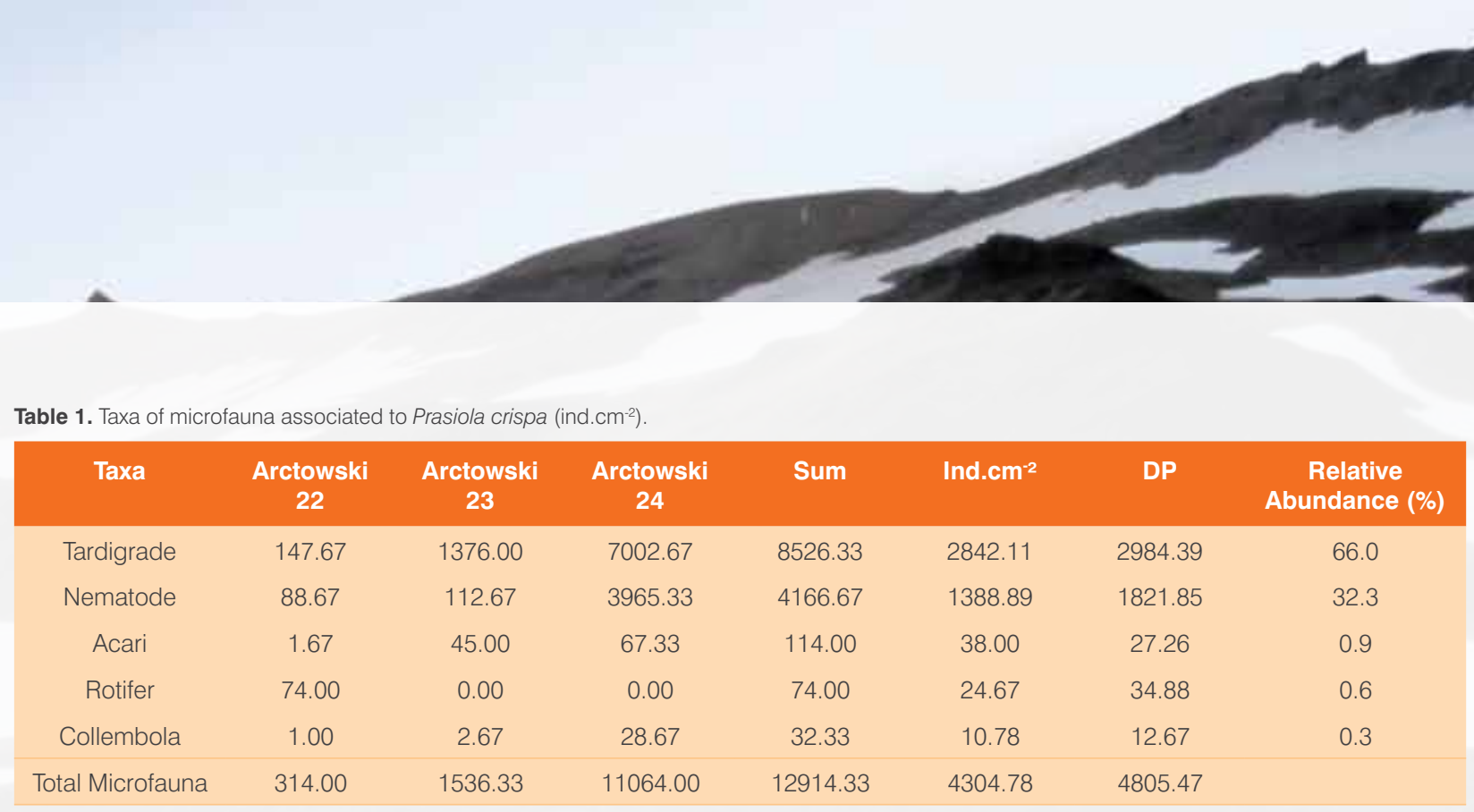

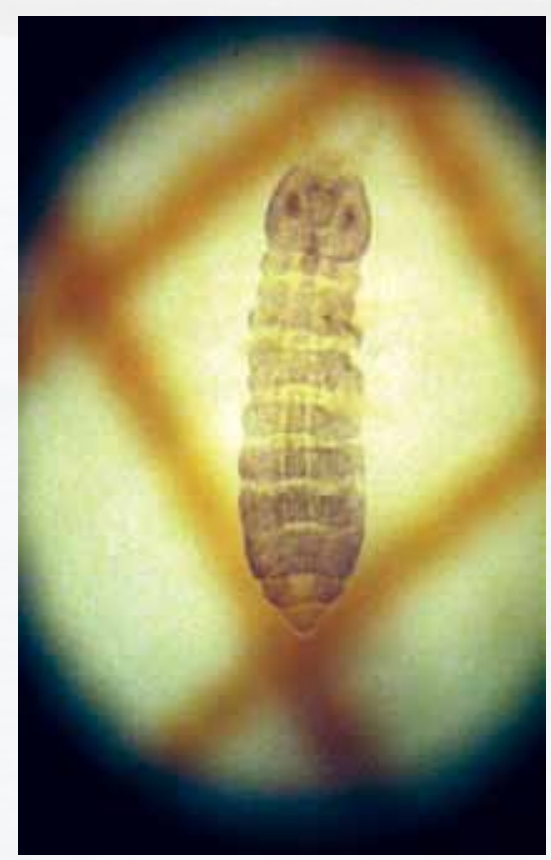

Figure 5. Friesia sp. (Collembola: Poduroidea: Frieseinae). Photo: Eduardo Abrantes

described as pertaining to the Antarctic Maritime region (Convey \& McInnes, 2005; Carey et al., 2008; Worland \& Lukesova, 2000) having ample presence throughout Antarctica. According to Convey and McInnes (2005), these terrestrial ecosystems dominated by Tardigrades, and organisms which would generally be ubiquitous, such as Nematode, can also very often be absent. Approximately 17 genera and 48 species of Tardigrade occur in the ice-melt regions of Sub-Antarctica and Antarctica.

The results obtained up to the present suggest that the density and the diversity of the microfauna of $P$. crispa can

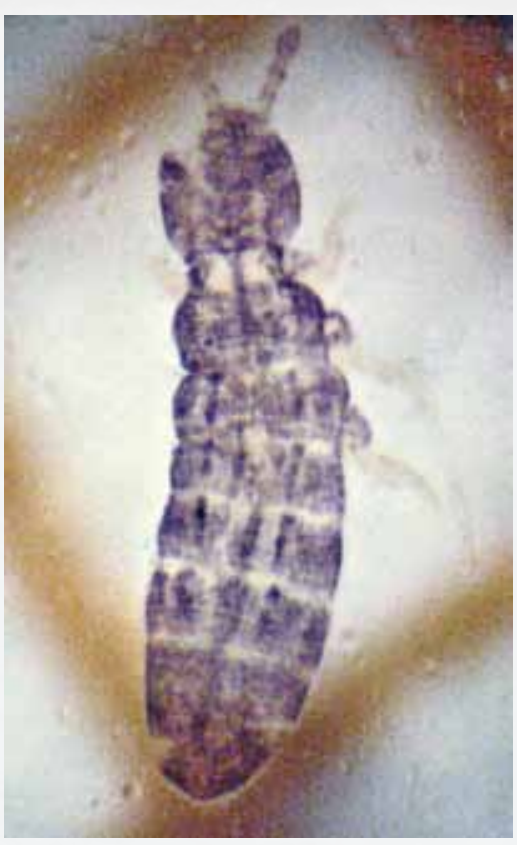

Figure 6. Cryptopygusantarticus (Colembola: Isotomidae: Anurophorinae). Photo: Eduardo Abrantes.

be conditioned to the presence of water from ice-melt and to the degree of humidity in the thallus of this alga. In the Antarctic Peninsula, the populations of microartropods are essentially limited by the availability of water, and not by the extreme cold (Convey et al., 2003; Hayward et al., 2004; Kennedy, 1993; McGeoch et al., 2006).

Recent studies have shown that global warming, in an indirect way, can significantly affect this micro-habitat, through the increase of the availability of water, which consequently influences in the transport of nutrients, affecting directly the productivity and development of 


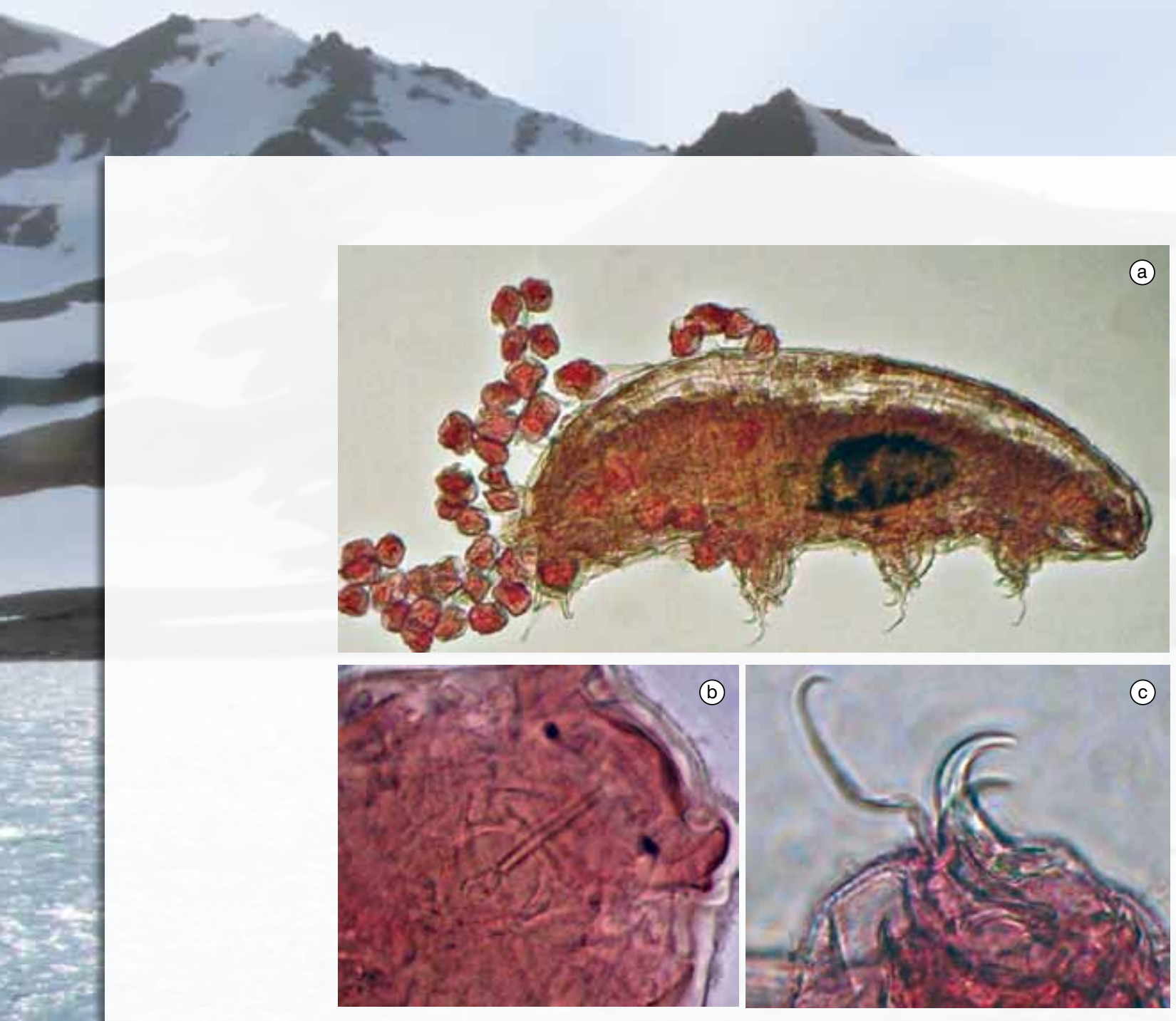

Figure 7. a) Hypsibiidae (Tardigrade: Eutardigrada); b) Detail of the bucco-pharynx area; c) claw characteristic of the family. Photos: Geyze Faria.

this alga (Wasley et al., 2006). The most important factor determining their distribution is the presence of water in liquid form, to which organisms must have at least occasional access in order to grow and reproduce (Wharton \& Marshall, 2009). The latter could have a very important effect on the diversity of microfauna which uses $P$. crispa as a substrate, as shelter and even as food, as is the case of the Collembola Cryptopygus antarcticus, which has this alga as its preferential food. There is still, weak evidence that the anthropogenic activity could influence the population distribution of Tardigrade (Steiner, 1994; Hohl et al., 2001).

Furthermore, recent research studies have shown that Prasiola crispa possesses potential bioactive substances for insecticide activity (Posser et al., in this volume), which is indicative of how important it is to increase the knowledge about this alga and all the associated microfauna related to it. Moreover, Tardigrades have very little economic impact on humans. Their ability to undergo cryptobiosis has created an interest in the medical community and approaches to cell or organ preservation in humans have been tested. Due to the potential medical applications and their pivotal phylogenetic position, branching from the stem lineage that led to arthropods, there has been a renewed interest in the biology of Tardigrades at the genomic and proteomic levels. As studies of Tardigrade distribution and ecology become more complete they may yet become a useful tool for biogeography (Pilato \& Binda, 2001).

\section{Acknowledgements}

We thank the National Institute of Science and Technology Antarctic Environmental Research (INCT-APA) for financing this work (CNPq process no 574018/2008-5 and FAPERJ, process $\left.n^{\circ} \mathrm{E}-16 / 170.023 / 2008\right), \mathrm{CNPq}$ and CAPES/ FAPERJ for the research fellows. 


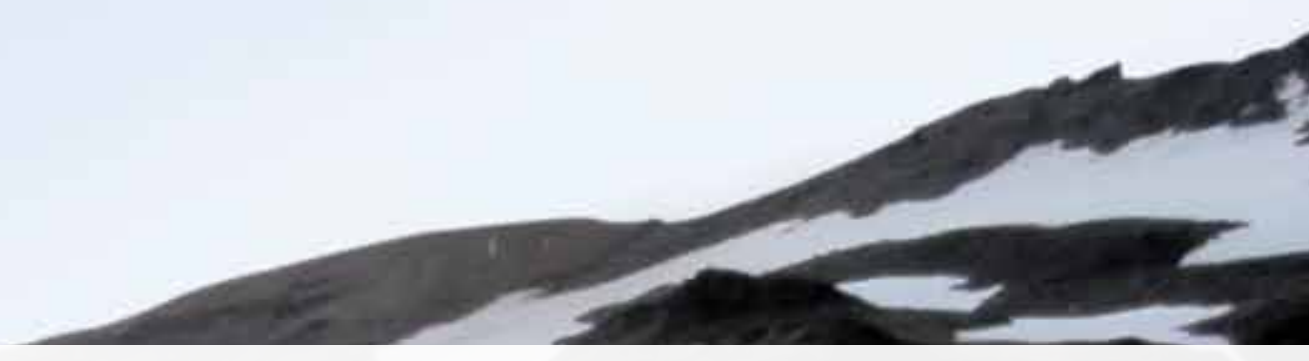

\section{References}

Convey, P.; Block, W. \& Peat, H. J. Soil arthropods as indicators of water stress in Antarctic terrestrial habitats? Global Change Biology, 9, 1718-1730. 2003.

Convey, P. \& McInnes, S. J. Exceptional tardigrade-dominated ecosystems in Ellsworth Land, Antarctica. Ecology, 86, 519-52. 2005.

Convey P. \& Stevens M. I. Antarctic biodiversity. Science, 317, 1877-1878. (doi:10.1126/science.1147261). 2007

Convey, P.; Gibson, J. A. E.; Hillenbrand, C. D.; Hodgson, D. A.; Pugh, P. J. A.; Smellie, J. L.; Stevens, M. I. Antarctic terrestrial life-challenging the history of the frozen continent? Biological Reviews, 83, 103-117. (doi:10.1111/j.1469-185X.2008.00034.x) 2008

Convey, P.; Bindschadler, R.; Prisco, G. di; Fahrbach, E.; Gutt, J.; Hodgson, D. A.; Mayewski, P. A.; Summerhayes, C. P. \& Turner, J. Antarctic climate change and the environment. Antarctic Science, 21, 541. 2009

Chow, S. L. \& Convey, P., Spatial and Temporal variability across life's hierarchies in the terrestrial Antarctic. Philosophical Transactions of The Royal Society B : Biological Science, 362: 2307-2331, 2007.

Hayward, S. A. L.; Rinehart, J. P.; Sandro, L. H.; Lee, R. E. \& Denlinger, D. L. Slow dehydration promotes desiccation and freeze tolerance in the Antarctic midge Belgica antarctica. Journal of Experimental Biology, 210, 836-844. 2007.

Hohl, A. M.; Miller, W. R. \& Nelson, D. R. The distribution of tardigrades upwind and downwind of a Missouri Coal-Burning Power Plant. Zoologischer Anzeiger, 240, 395-401. 2001.

Kennedy, A. Water as a limiting factor in the Antarctic Terrestrial Environment: A Biogeographical Synthesis. Arctic and Alpine Research, Vol. 25, n 4, pp. 308-315 <http://www.jstor.org/stable/1551914> 1993.

McGeoch, M. A.; Chown, S. L. \& Kalwij, J. M. A global indicator for biological invasion. Conservation Biology, 20, $1635-1646$. 2006.

Pilato, G. \& Binda, M. G. Biogeography and limno-terrestrial tardigrades: are they truly incompatible binomials? Zoologischer Anzeiger, 240: 511-516. 2001.

Schulte, G. G.; Elnitsky, M. A.; Benoit, J.B.; Denlinger, D. L. \& Lee Jr., R. E. Extremely large aggregations of collembolan eggs on Humble Island, Antarctica: a response to early seasonal warming? Polar Biology, 31: 889-892. 2008.

Sinclair, B. J., Scott, M. B., Klok, C. J., Terblanche, J. S., Marshall, D. J., Reyers, B.\& Chown, S. L. Determinants of terrestrial arthropod community composition at Cape Hallett, Antarctica. Antarctic Science, 18(3): 303-312. 2006.

Steiner, W. A. The influence of air pollution on moss dwelling animals: 4. Seasonal and long-term fluctuations of rotifer, nematode and tardigrade populations. Revue Suisse de Zoologie, 101: 1017-1031. 1994.

Stevens, M. I. \& Hogg, I. D. Expanded distributional records of Collembola and Acari in southern Victoria Land, Antarctica. Pedobiologia, 46: 485-495. 2002.

Wasley, J.; Robinson, S. A.; Lovelock, C. E. \& Popp, M. Some like it wet - biological characteristics underpinning tolerance of extreme water stress events in Antarctic bryophytes. Functional Plant Biology, 33, 44. 2006.

Wharton, D. A. \& Marshall, C. J. How do terrestrial Antarctic organisms survive in their harsh environment? Journal of Biology, 8, 9. doi: 10.1186/jbiol142. 2009.

Worland, M. R. \& Lukesová, A. The effect of feeding on specific soil algae on the cold hardiness of two Antarctic microarthropods (Alaskozetes antarcticus and Cryptopygus antarcticus). Polar Biology, 23:766-774. 2000. 